\title{
Jet Impingement Cooling of a Rotating Hot Circular Cylinder with Hybrid Nanofluid under Multiple Magnetic Field Effects
}

\author{
Badreddine Ayadi $^{1}$, Fatih Selimefendigil ${ }^{2, *}$, Faisal Alresheedi ${ }^{3}$, Lioua Kolsi ${ }^{1,4} \mathbb{D}^{\text {, }}$, Walid Aich ${ }^{1,5}$ \\ and Lotfi Ben Said 1,6 (iD
}

1 Department of Mechanical Engineering, College of Engineering, University of Ha'il, Ha'il City 81451, Saudi Arabia; b.ayadi@uoh.edu.sa (B.A.); lioua_enim@yahoo.fr (L.K.); aich_walid@yahoo.fr (W.A.); bensaid_rmq@yahoo.fr (L.B.S.)

2 Department of Mechanical Engineering, Celal Bayar University, Manisa 45140, Turkey

3 Department of Physics, College of Science, Qassim University, Buraidah 51452, Saudi Arabia; f.alresheedi@qu.edu.sa

4 Laboratory of Metrology and Energy Systems, National Engineering School of Monastir, University of Monastir, Monastir City 5000, Tunisia

5 Materials, Energy and Renewable Energies Research Unit, Faculty of Sciences, University of Gafsa, Gafsa 2112, Tunisia

6 Laboratory of Electro-Mechanical Systems (LASEM), National Engineering School of Sfax, University of Sfax, Sfax 3038, Tunisia

* Correspondence: fatih.selimefendigil@cbu.edu.tr; Tel.: +90-236-241-21-44; Fax: +90-236-241-21-43

Citation: Ayadi, B.; Selimefendigil, F.; Alresheedi, F.; Kolsi, L.; Aich, W.; Said, L.B. Jet Impingement Cooling of a Rotating Hot Circular Cylinder with Hybrid Nanofluid under Multiple Magnetic Field Effects. Mathematics 2021, 9, 2697. https://doi.org/ $10.3390 /$ math 9212697

Academic Editor: Arturo Hidalgo

Received: 24 September 2021

Accepted: 21 October 2021

Published: 24 October 2021

Publisher's Note: MDPI stays neutral with regard to jurisdictional claims in published maps and institutional affiliations.

Copyright: (c) 2021 by the authors. Licensee MDPI, Basel, Switzerland. This article is an open access article distributed under the terms and conditions of the Creative Commons Attribution (CC BY) license (https:// creativecommons.org/licenses/by/ $4.0 /)$.
Abstract: The cooling performance of jet impinging hybrid nanofluid on a rotating hot circular cylinder was numerically assessed under the effects of multiple magnetic fields via finite element method. The numerical study was conducted for different values of Reynolds number $(100 \leq \operatorname{Re} \leq 300)$, rotational Reynolds number $(0 \leq$ Rew $\leq 800)$, lower and upper domain magnetic field strength $(0 \leq \mathrm{Ha} \leq 20)$, size of the rotating cylinder $(2 \mathrm{w} \leq r \leq 6 \mathrm{w})$ and distance between the jets $(6 \mathrm{w} \leq \mathrm{H}$ $\leq 16 \mathrm{w})$. In the presence of rotation at the highest speed, the $\mathrm{Nu}$ value was increased by about $5 \%$ when $\operatorname{Re}$ was increased from $\operatorname{Re}=100$ to $\operatorname{Re}=300$. This value was $48.5 \%$ for the configuration with the motionless cylinder. However, the rotations of the cylinder resulted in significant heat transfer enhancements in the absence or presence of magnetic field effects in the upper domain. At Ha1 = 0 , the average $\mathrm{Nu}$ rose by about $175 \%$, and the value was $249 \%$ at $\mathrm{Ha} 1=20$ when cases with the cylinder rotating at the highest speed were compared to the motionless cylinder case. When magnetic field strengths of the upper and lower domains are reduced, the average Nu decreases. The size of the cylinder is influential on the flow dynamics and heat transfer when the cylinder is rotating. An optimum value of the distance between the jets was obtained at $\mathrm{H}=14 \mathrm{w}$, where the Nu value was highest for the rotating cylinder case. A modal analysis of the heat transfer dynamics was performed with the POD technique. As diverse applications of energy system technologies with impinging jets are available, considering the rotations of the cooled surface under the combined effects of using magnetic field and nanoparticle loading in heat transfer fluid is a novel contribution. The outcomes of the present work will be helpful in the initial design and optimization studies in applications from electronic cooling to convective drying, solar power and many other systems.

Keywords: MHD flow; impinging jets; rotating surface; surface rotation; hybrid nanofluid; finite element method

\section{Introduction}

Jet impinging heat transfer (j-imp HT) applications arise in different thermal engineering systems. Some examples include drying, solar power, electronic cooling, textiles and turbine blade cooling. In solar power applications, photovoltaic panel thermal management can be achieved by using impinging jets. Locally higher HT coefficients can be achieved. The coupled interactions among the established recirculations, pressure gradients and 
thermal field within the system make the system's performance analysis very complex in the presence of complex geometries. Effects of different geometric factors and operating parameters on the j-imp HT characteristics were analyzed for single and multiple jets Garimella [1]. Many review works have been devoted to analyzing the convective HT with impinging jets: j-imp HT in the turbulent regime for a single circular j-imp [2], air j-imp HT in food processing [3] and j-imp in solar power [4].

The effectiveness of using liquid jets can be enhanced by introducing nano-sized particles in HT fluid, forming nanojets. In thermal energy systems, nanofluids (N-F) are widely used in different applications, such as solar, refrigeration and thermal management in diverse HT systems [5-10]. The potential benefits of using N-Fs in those systems have been shown. In j-imp HT, N-Fs have been used, and improved HT characteristics were reported in many studies [11-15]. In a review Mohammadpour and Lee [16], the effects of using N-Fs on the HT improvements for conventional and swirl type impinging jets were analyzed. Some challenges, such as nanoparticle agglomeration and pressure drop, were mentioned with future trends and applications. In the experimental work of Teamah et al. [17], an up to $62 \%$ increment in the HT coefficient was obtained with nanofluid as compared to water for $\mathrm{j}$-imp on a flat surface. Using $\mathrm{CuO}$ nanoparticles delivered the best performance. Naphon and Wiriyasart [18] experimentally analyzed the nano j-imp HT in a micro channel heat sink by using $\mathrm{TiO}_{2}$ nanoparticles. They observed convective HT incrementation by about $18.56 \%$ at a nanofluid concentration of $0.015 \%$, and no additional pressure drop was obtained. Some other aspects of j-imp HT with nanofluids have been considered, such as moving surface [19], flow pulsation [20,21], boiling HT [22,23] and surface corrugation $[24,25]$. The form of the target surface is also very important in j-imp HT [26,27]. Rotating objects have been considered in several convective HT applications. Size, rotational speed and the location of the object were found to be effective in altering the flow dynamics and HT characteristics [28-30]. Some studies considered the rotations of the surface with impinging jets [31-34].

The application of a magnetic field $(\mathrm{MaF})$ in engineering is encountered in diverse applications, such as in geothermal energy, coolers of nuclear reactors, micro pumps, continuous casting processes and many others $[35,36]$. Finite element method (FEM) simulations of configurations with MaF effects have been proposed in diverse studies [37-40], and extensive literature on the electromagnetic forward problem computation via the FEM is available [41-43]. In convective HT, applications have also been considered with imposed external MaF for thermal management and flow control [44-49]. The effectiveness of using $\mathrm{MaF}$ was further elaborated by using nano-sized particles in HT fluid [50-53]. In j-imp $\mathrm{HT}, \mathrm{MaF}$ effects were considered in several studies [54,55] and with nanojets $[56,57]$. In those studies, reduction in the convective HT was achieved, and adding nanoparticles improved the HT. The suppression of the vortices and potential of the HT entrancement can be achieved with MaF effects depending upon the geometry of the configuration, such as flow over step, or in cavity flows [58-60]. As different geometries and various corrugation levels of the impinging surfaces are available with impinging jets, there is potential for $\mathrm{MaF}$ to improve the convective HT.

The present study deals with the confined slot j-imp HT and flow features for a rotating surface located in between the domains that are under the effects of MaF of different strengthens. Two opposing cold jets were used for cooling the hot rotating cylinder, and MaFs in different domains were uniform and inclined. A hybrid nanofluid was used, as the HT fluid and the experimental data were available for the effective viscosity and thermal conductivity of the nanofluid. As there are many applications of impinging jets in different energy system technologies, the use of multiple MaF effects for a jet impinging on a hot rotating surface is a novel contribution. The MaF effects can be available within systems such as continuous casting systems for molten metals and nuclear reactor cooling, or they can be imposed as external sources for flow and HT control. The use of nanofluids in a jet configuration with accurate descriptions of nanofluid property relations improves the HT performance and gives more flexibility for convective HT control of the thermo-fluid 
system. In this study, modal analysis was used for exploring the heat transfer dynamics of the j-imp system under multiple MaF effects, and the details are explained in the following subsection of the manuscript.

\section{Mathematical Model}

Jet impingement (j-imp) cooling performance with hybrid nanofluid (N-F) is explored for a rotating hot cylinder exposed to jets in opposite directions, as shown in Figure 1. A hot rotating cylinder (R-C) with radius $r$ is used, with a rotational speed of $\omega$. Single confined jets emerging from nozzles with width $w$ are considered. The R-C is in the middle of the computational domain, and the upper and lower parts are exposed to uniform MaF with strengths of $\vec{B}_{1}$ and $\vec{B}_{2}$. The inclinations of the MaF are denoted by $\gamma_{1}$ and $\gamma_{2}$. The hot cylinder is maintained at a constant temperature of $T_{h}$; the cold fluid streams at temperature $T_{\mathcal{c}}$ and velocity $u_{c}$ enter the domains. The distance of jet inlets to the interface is $H$, and the lengths of the upper and lower plates, which are adiabatic, is $L$.

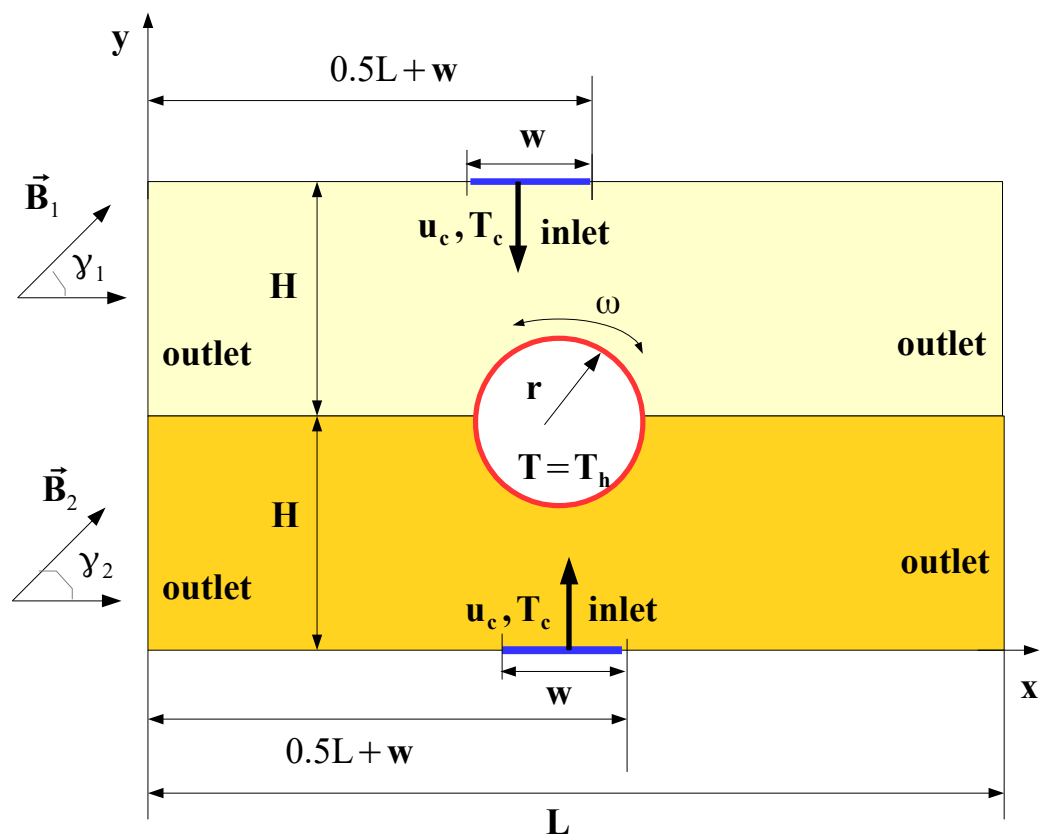

Figure 1. Model description with boundary conditions.

As the HT fluid, hybrid N-F is used. It is $40 \%$ ethylene glycol and contains $\mathrm{TiO}_{2}-\mathrm{Al}_{2} \mathrm{O}_{3}$ binary nanoparticles. Experimental data were used to derive viscosity $\left(\mu_{n f}\right)$ and thermal conductivity $\left(k_{n f}\right)$ correlations for nanoparticle concentrations from 0.02 to $0.1 \%$ [61]. They are given by the following expressions [61]:

$$
\begin{gathered}
\mu_{n f}=7.1074+3.65 \phi-0.14097 T+0.05176 \phi T+0.907 \phi \phi+0.00092 T^{2}, \\
k_{n f}=0.386 e^{(2.27 \phi+0.002939 T)} .
\end{gathered}
$$

They are valid for an 80:20 mixture ratio of $\mathrm{TiO}_{2}-\mathrm{Al}_{2} \mathrm{O}_{3}$ in $40 \%$ EG. The valid temperature range is between 30 and $80{ }^{\circ} \mathrm{C}$ and concentration is between $0.02 \%$ and $0.1 \%$. $\mathrm{N}-\mathrm{F}$ behaves as Newtonian [61]. In the modeling with MaF, Joule heating, induced MaF effects and displacement currents are not considered. The viscous dissipation and natural convection effects are also ignored. The conservation equations are given as:

$$
\frac{\partial u}{\partial x}+\frac{\partial v}{\partial y}=0
$$




$$
\begin{gathered}
u \frac{\partial u}{\partial x}+v \frac{\partial u}{\partial y}=-\frac{1}{\rho_{n f}} \frac{\partial p}{\partial x}+v_{n f}\left(\frac{\partial^{2} u}{\partial x^{2}}+\frac{\partial^{2} u}{\partial y^{2}}\right)+\frac{\sigma_{n f} B_{i}^{2}}{\rho_{n f}}\left(v \cos \gamma_{i} \sin \gamma_{i}-u \sin ^{2} \gamma_{i}\right) \\
u \frac{\partial v}{\partial x}+v \frac{\partial v}{\partial y}=-\frac{1}{\rho_{n f}} \frac{\partial p}{\partial y}+v_{n f}\left(\frac{\partial^{2} v}{\partial x^{2}}+\frac{\partial^{2} v}{\partial y^{2}}\right)+\frac{\sigma_{n f} B_{i}^{2}}{\rho_{n f}}\left(u \cos \gamma_{i} \sin \gamma_{i}-v \cos ^{2} \gamma_{i}\right) \\
u \frac{\partial T}{\partial x}+v \frac{\partial T}{\partial y}=\alpha_{n f}\left(\frac{\partial^{2} T}{\partial x^{2}}+\frac{\partial^{2} T}{\partial y^{2}}\right) .
\end{gathered}
$$

In the above representations, $B_{i}$ and $\gamma_{i}$ denote MaF strength and inclinations for upper $i=1$ and lower $i=2$ domains, respectively. Here, $\sigma_{n f}$ and $\alpha_{n f}$ are the electrical conductivity and diffusivity of the nanofluid.

The boundary conditions in dimensional form are written as:

- At the inlet,

$$
u=0, v=u_{c}, T=T_{c} \text {. }
$$

- $\quad$ At the exit:

$$
\frac{\partial u}{\partial x}=0, \quad \frac{\partial v}{\partial x}=0, \quad \frac{\partial T}{\partial x}=0
$$

- Top and bottom plate are adiabatic and stationary:

$$
u=v=0, \frac{\partial T}{\partial y}=0
$$

- On the rotating cylinder surface:

$u=-\omega\left(y-y_{c}\right), v=\omega\left(x-x_{c}\right), T=T_{h}$

- At the interface between the upper and lower domains:

$$
u_{1}=u_{2}, v_{1}=v_{2},\left(\frac{\partial T}{\partial n}\right)_{1}=\left(\frac{\partial T}{\partial n}\right)_{2}
$$

At the exit of the channels, pressure outlet boundary conditions are utilized.

The following physical, non-dimensional parameters are relevant:

$$
\operatorname{Re}=\frac{\rho u_{c} D_{h}}{\mu}, \operatorname{Pr}=\frac{v}{\alpha}, \quad \mathrm{Ha}_{i}=B_{i} D_{h} \sqrt{\frac{\sigma}{\mu}}
$$

where $\rho, v, \alpha, \mu$ and $\sigma$ denote the density, kinematic viscosity, thermal diffusivity, dynamic viscosity and electrical conductivity of the nanofluid. The characteristic length based on the slot width is given by $D_{h}=2 \mathrm{w}$.

As the solver, the Galerkin weighted residual FEM is used. In the formulation, residual $R$ is obtained after using the approximated field variables in the equations. Different ordered Lagrange FEMs are utilized for approximations of field variable $(F)$ :

$$
F=\sum_{r=1}^{N^{s}} \Phi_{r}^{s} G_{k}
$$

where $\Phi^{r}$ is the shape function and $G$ denotes the nodal value. The residual is forced to be zero in an average manner as:

$$
\int_{V} W R d V=0,
$$

where $W$ represents the weight function, and $R$ is the residual. Artificial diffusion with the streamline upwind Petrov-Galerkin method (SUPG) is used in the solver to handle local numerical instabilities. The biconjugate gradient stabilized iterative method solver (BICGStab) is used for fluid flow and heat transfer modules of code. The convergence criterion of $10^{-7}$ was assumed when converged solution results were achieved.

The cooling performance can be represented in terms of Nusselt number $(\mathrm{Nu})$. Local and average $\mathrm{Nu}$ are given as:

$$
\mathrm{Nu}_{s}=\frac{h_{s} D_{h}}{k_{n f}}=-\frac{D_{h}}{T_{h}-T_{c}} \frac{\partial T}{\partial s} w^{\prime}, \quad \mathrm{Nu}_{m}=\frac{1}{S} \int_{0}^{S} \mathrm{Nu}_{s} d s .
$$


where $h_{s}$ and $S$ denote the local heat transfer coefficient and total length along the circumferential of the hot cylinder; $D_{h}$ is the hydraulic diameter.

Numerical simulations were checked for grid independency. Numerical tests were conducted for different grid sizes, and results are given in Figure 2a for the variations of the average $\mathrm{Nu}$ at two different $\mathrm{MaF}$ strengths of the upper domain. Grid system Gr4 with 115,534 elements was selected, and the distribution of the grid near the R-C is presented in Figure 2b.

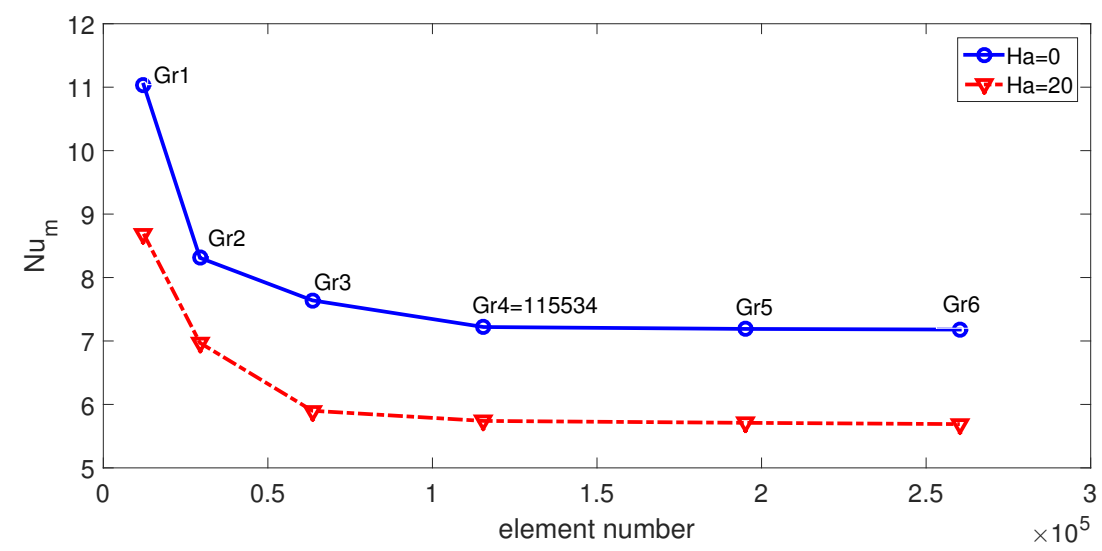

(a)

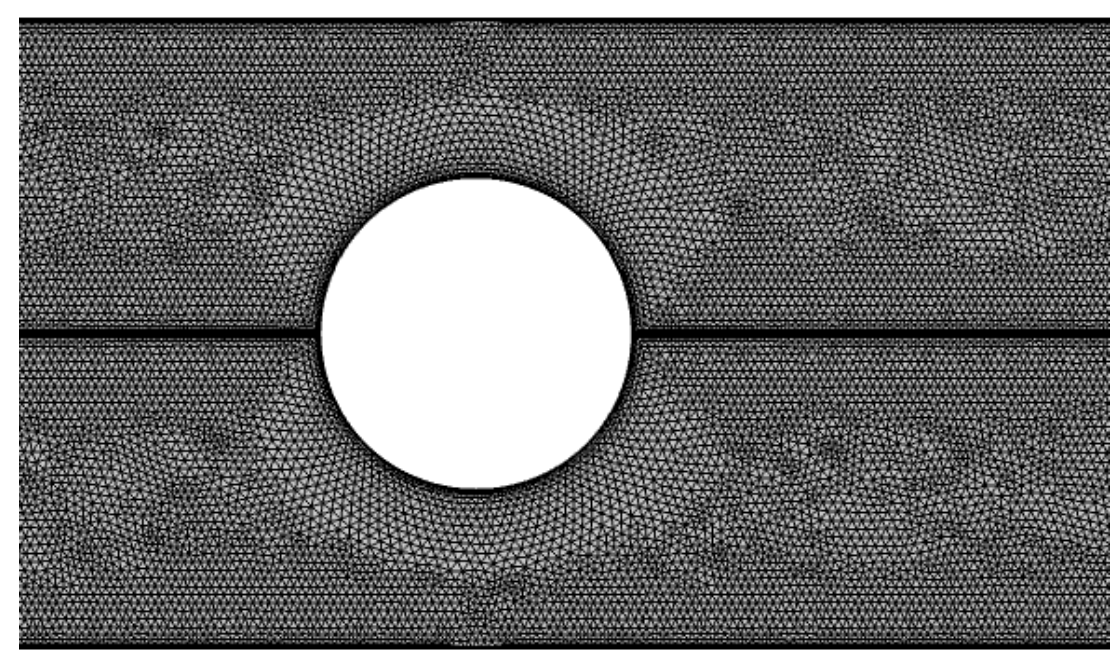

(b)

Figure 2. Grid independence test results: Average $\mathrm{Nu}$ variations for different grid sizes at two MaF strengths of the upper domain (a) and grid distribution (b) $(\operatorname{Re} 1=\operatorname{Re} 2=200, \operatorname{Rew}=100, \mathrm{Ha} 2=10$, $\mathrm{H}=8 \mathrm{w}, \mathrm{r}=4 \mathrm{w})$.

The numerical code was validated by using different studies available in the literature. In the first study, numerical results from the work of Sahoo and Sharif [62] for j-imp cooling of a surface held at constant heat flux were used. Figure 3a presents the comparison results of average $\mathrm{Nu}$ for two different aspect ratios (AR) at $\mathrm{Re}=500$. The deviations are $0.6 \%$ and $1.3 \%$ from the reference solution at $\mathrm{AR}=4$ and $\mathrm{AR}=10$. Another validation was performed by using the confined slot j-imp cooling results available in $[63,64]$. Table 1 presents the stagnation point $\mathrm{Nu}$ at $\mathrm{Re}=300$. The highest deviation was $1.55 \%$, from the results of [64]. Finally, the effect of using MF in convective HT was considered within a cavity by using the results of [65]. Comparison of average $\mathrm{Nu}$ for different MF strengths is shown in Figure 3b at $\mathrm{Gr}=2 \times 10^{5}$. The highest difference was found to be below $5 \%$ when the present solver 
results were compared. The results showed that the present code is capable of simulating the effects of MF in convective HT and j-imp HT.

Table 1. Stagnation $\mathrm{Nu}$ comparisons for confined slot $\mathrm{j}$-imp at $\mathrm{Re}=300$.

\begin{tabular}{cc}
\hline Reference Study & $\mathbf{R e}=\mathbf{3 0 0}$ \\
\hline Present study & 9.81 \\
Ref. [63] & 9.85 \\
Ref. [64] & 9.66 \\
\hline
\end{tabular}

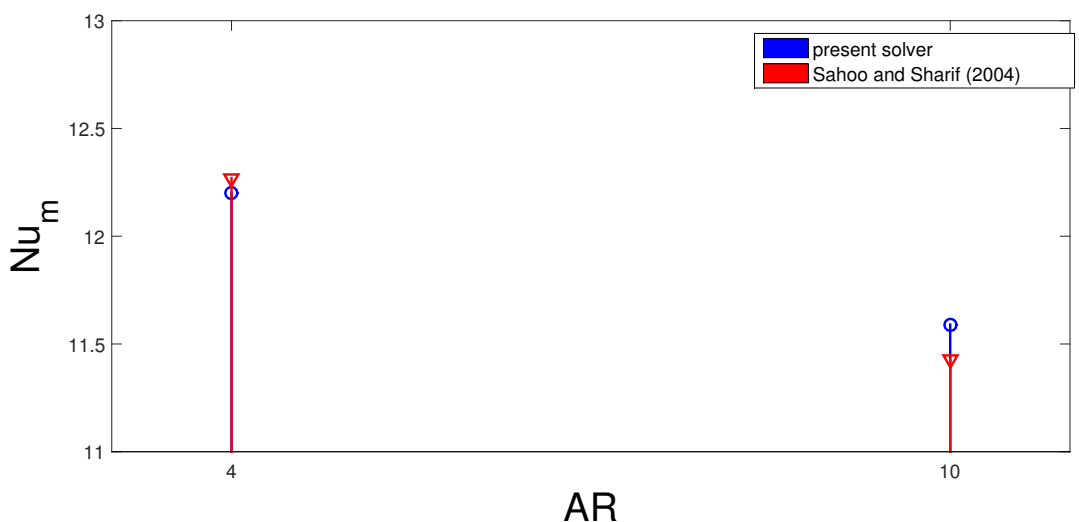

(a)

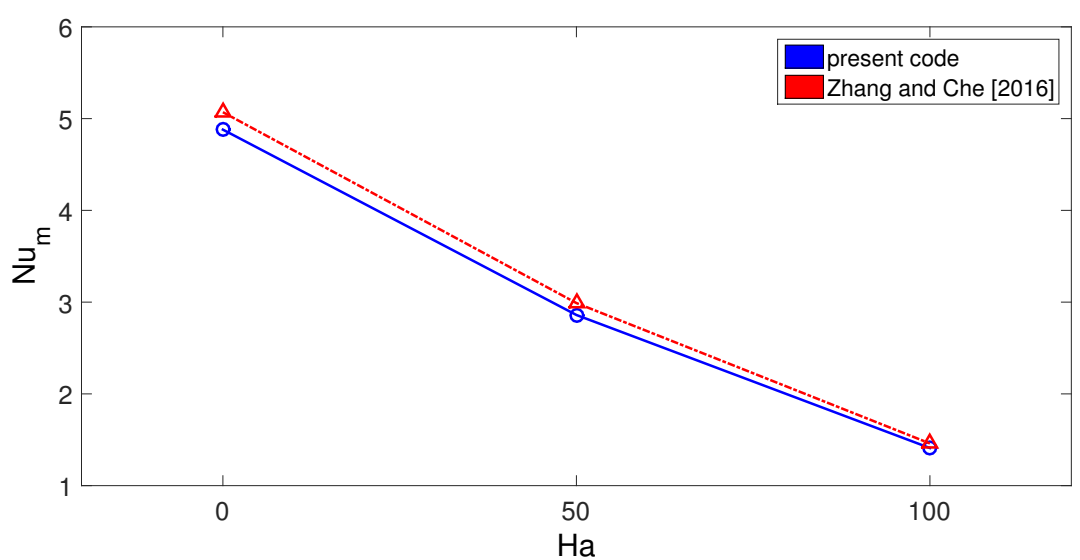

(b)

Figure 3. The average Nu comparison for slot j-im cooling at two values of aspect ratio (AR) where the surface is kept at an isothermal hot temperature (reference values of [62] were used) (a) and comparisons of average $\mathrm{Nu}$ for convective HT with varying MaF strengths (reference values of [65] were used) (b).

\section{Results and Discussion}

Coupled interactions between the multiple MaF effects, rotational surface and forced convection of hybrid N-F on the cooling performance were examined for j-imp on a hot rotating cylinder. The upper and lower domains of the were exposed to uniform MaF of different strengths while double jets of hybrid N-F were used for different parts of the rotating cylinder. The nanoparticle concentration was taken as between 0.02 to $0.1 \%$; the nanofluid behaved as a Newtonian fluid. The Reynolds number was between 100 and 300, and the unsteady flow effects were ignored. The MaF strengths and rotational Reynolds numbers were taken as $0 \leq \mathrm{Ha} \leq 20$ and $0 \leq$ Rew $\leq 800$. Modal analysis was used for the heat transfer dynamics. 


\subsection{Computational Fluid Dynamics Simulation Results}

Flow patterns are shown for different Re numbers in the absence (Figure 4a-c) and presence of (Figure $4 \mathrm{~d}-\mathrm{f}$ ) rotational surface effects. When rotations were not active, due to confinement and entrainment, vortices were established near the inlet zones. As the Re was increased, vortex size enlarged. As the rotational surface effects were considered, the vortices near the inlet region were distorted due to the rotations of the cylinder, and additional recirculation zones were observed near the hot cylinder. Effects of Rew on the flow pattern distributions in the absence and presence of $\mathrm{MaF}$ in the upper domain are shown in Figure $4 \mathrm{~g}-1$. When there were no MaF effects present, recirculation zones near the inlet and and secondary vortices at the interface on the upper part were observed. When rotations were introduced, on the top wall of the upper domain, multi-recirculation regions were established. At Rew $=800$, three vortices are shown adjacent to the upper domain top wall. As the MaF was imposed at the highest strength, suppression of the vortices in the upper region is shown for all Rew. Impacts of Re on the average Nu were weaker when rotational surface effects were considered at the highest speed, as shown in Figure 4m. For the case with a motionless cylinder, the average Nu rose by about $48.5 \%$, but this amount was only $5 \%$ when rotational surface effects were dominant. The rotations of the cylinder brought significant enhancement of the average $\mathrm{Nu}$ as compared to the motionless cylinder configuration in the absence and presence of MaF effects. The enhancements were $175 \%$ and $249 \%$ when rotational effects at the highest speed were compared with the cases of stationary cylinder at $\mathrm{Ha} 1=0$ and Ha1 $=20$, respectively (Figure $4 \mathrm{n}$ ).

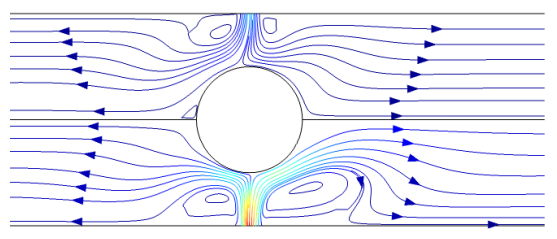

(a) $\operatorname{Re}=100, \operatorname{Rew}=0$

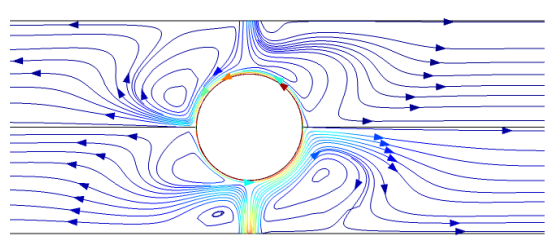

(d) $\operatorname{Re}=100, \operatorname{Rew}=800$

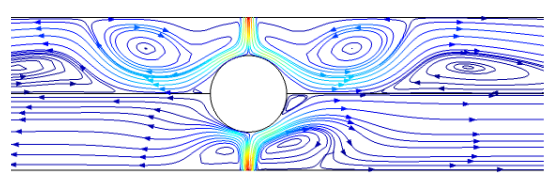

(g) Rew $=0$, Ha1 $=0$

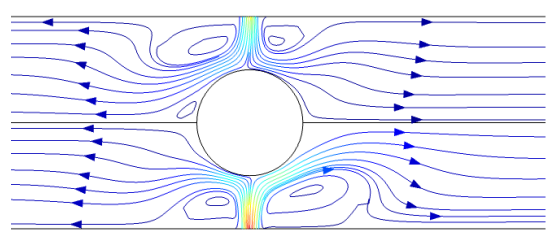

(b) $\operatorname{Re}=200, \operatorname{Rew}=0$

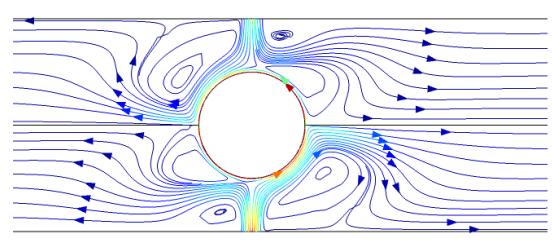

(e) $\operatorname{Re}=200, \operatorname{Rew}=800$

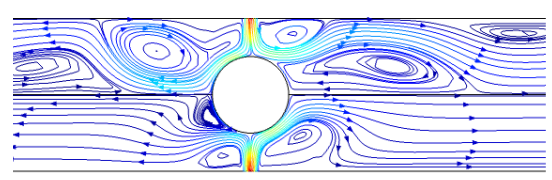

(h) Rew $=200$, Ha1 $=0$

Figure 4. Cont.

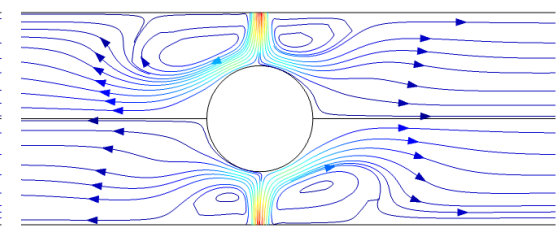

(c) $\operatorname{Re}=300$, Rew $=0$

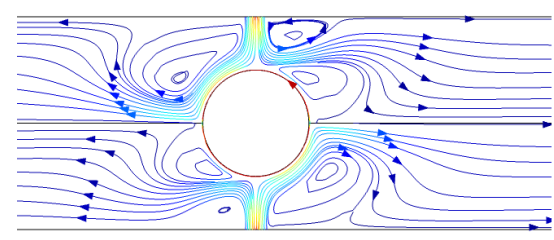

(f) $\operatorname{Re}=300, \operatorname{Rew}=800$

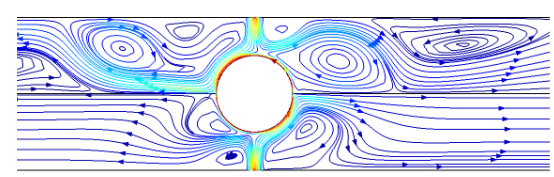

(i) $\operatorname{Rew}=800, \mathrm{Ha} 1=0$ 


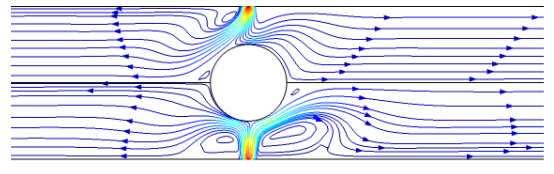

(j) Rew =0, Ha1 = 20

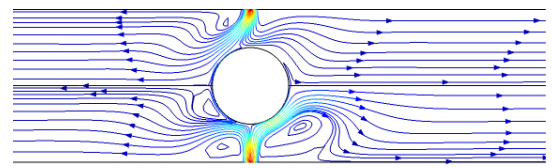

(k) Rew $=200$, Ha1 $=20$

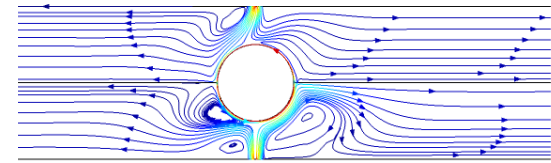

(1) Rew $=800$, Ha1 $=20$

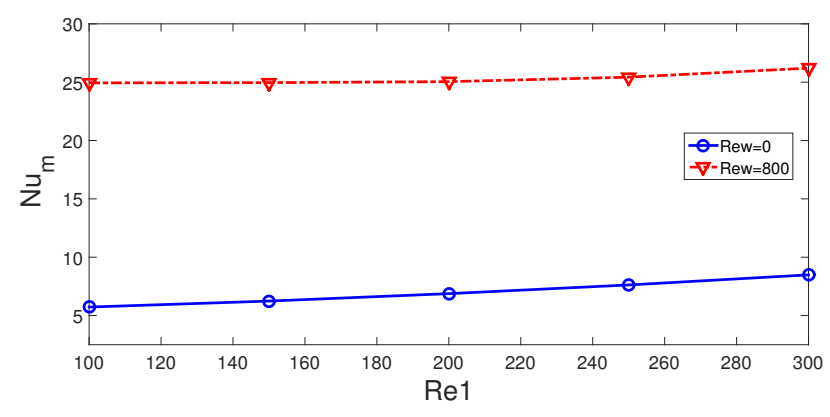

(m) $\mathrm{Ha} 1=\mathrm{Ha} 2=7.5$

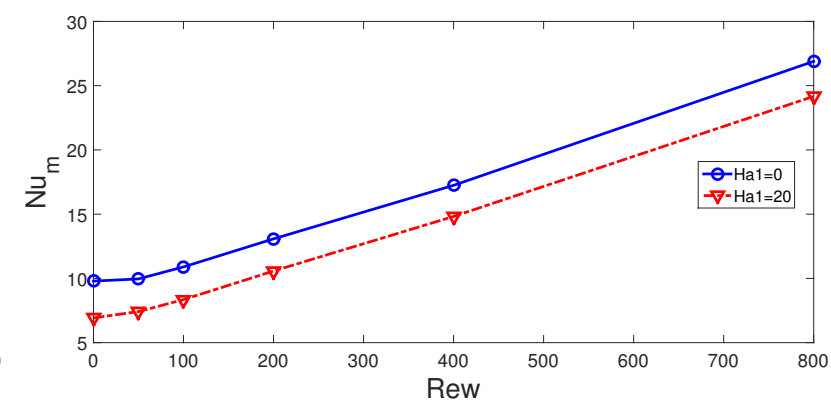

(n) $\operatorname{Re} 1=\operatorname{Re} 2=300$, Ha2 $=7.5$

Figure 4. Effects of Re on the streamline variations under the motionless $(\mathbf{a}-\mathbf{c})$ and rotating $(\mathbf{d}-\mathbf{f})$ cylinder impacts $(\mathrm{Ha} 1=7.5$, $\mathrm{Ha} 2=7.5, \mathrm{H}=8 \mathrm{w}, \mathrm{r}=4 \mathrm{w})$. Effects of Rew on the streamline variations in the absence $(\mathrm{g}-\mathbf{i})$ and presence (j-1) of upper domain $\operatorname{MaF}(\operatorname{Re} 1=300, \operatorname{Re} 2=300, \mathrm{Ha} 2=7.5, \mathrm{H}=8 \mathrm{w}, \mathrm{r}=4 \mathrm{w})$; average Nu variations with changes in $\operatorname{Re} 1(\mathbf{m})$ and $\operatorname{Rew}(\mathbf{n})$ $(\mathrm{H}=8 \mathrm{w}, \mathrm{r}=4 \mathrm{w})$.

The suppression of the vortices within different domains by imposing MaF of various strengths is shown in Figure 5a-f for different (Ha1, Ha2) combinations. The computational domain is characterized by multiple recirculations near the inlet zones and interface boundaries when no MaF is present in the system. As is shown in Figure $5 \mathrm{a}-\mathrm{c}$, the upper zone recirculation regions were suppressed as Ha1 increased. The vortex size and its number can be adjusted by changing the MaF strengths of the upper and lower domains. The impacts of $\mathrm{MaF}$ on the average $\mathrm{Nu}$ variation are shown in Figure $5 \mathrm{~g}$ for different combinations of upper and lower domain MaF strengths. The average $\mathrm{Nu}$ decreased with higher Ha1 or Ha2 values. As the MaF strength increased, the suppression of the vortices was observed within the domains, but the flow field was retarded and convective heat transfer was reduced. The trends in the average $\mathrm{Nu}-\mathrm{Ha} 1$ curves are similar for different $\mathrm{Ha} 2$ values. When cases in the absence $((\mathrm{Ha} 1, \mathrm{Ha} 2)=(0,0))$ and presence of MaF effects at the highest strength $((\mathrm{Ha} 1, \mathrm{Ha} 2)=(20,20))$ are compared, reductions in average $\mathrm{Nu}$ by $54.5 \%$ are obtained. Reductions in the convective heat transfer with MaF have been shown in various studies for impinging jets. However, in this work, multiple domains were under the effects of MaF with different strengths for impinging jet cooling.

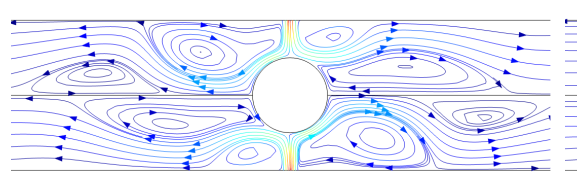

(a) $\mathrm{Ha} 1=0, \mathrm{Ha} 2=0$

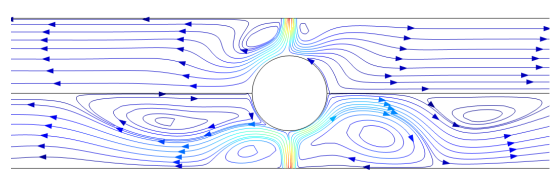

(b) $\mathrm{Ha} 1=10, \mathrm{Ha} 2=0$

Figure 5. Cont.

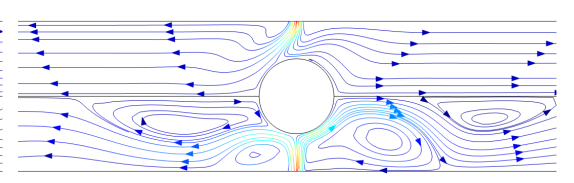

(c) $\mathrm{Ha} 1=20, \mathrm{Ha} 2=0$ 


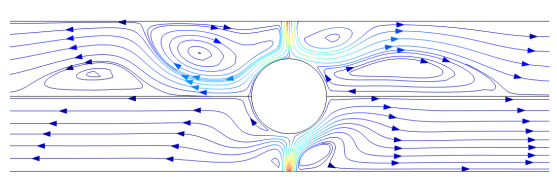

(d) $\mathrm{Ha} 1=0, \mathrm{Ha} 2=10$

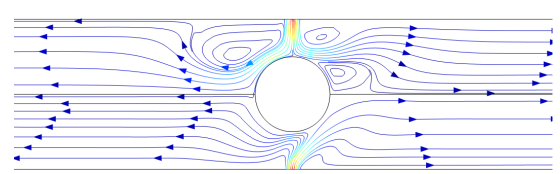

(e) $\mathrm{Ha} 1=0, \mathrm{Ha} 2=20$

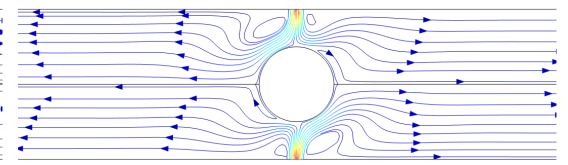

(f) $\mathrm{Ha} 1=10, \mathrm{Ha} 2=10$

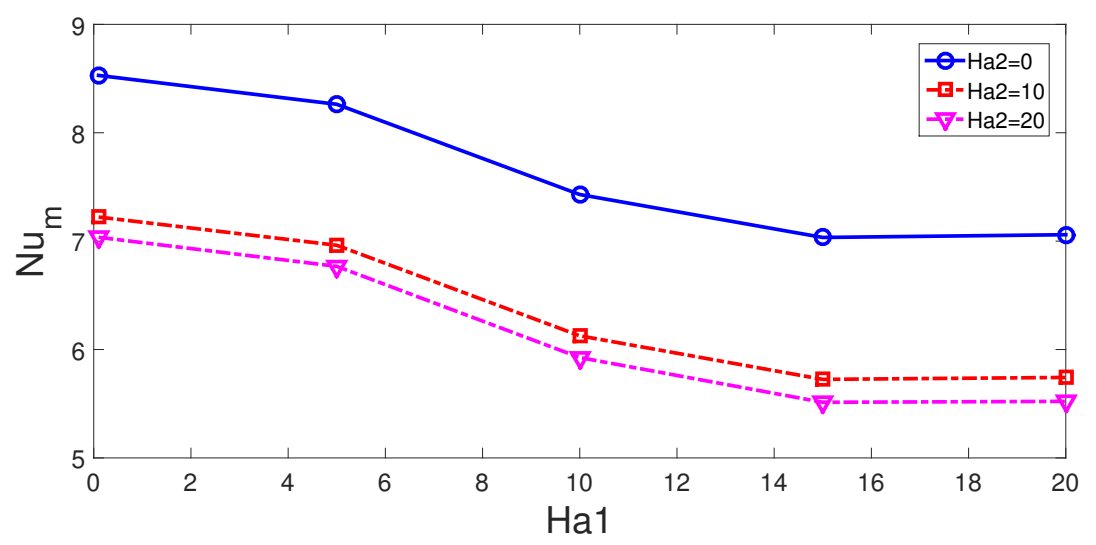

(g)

Figure 5. Impacts of MaF strength of the domains (Ha1, Ha2) on the distribution of streamlines (a-f) and average $\mathrm{Nu}$ variations $(\mathrm{g})(\operatorname{Re} 1=\operatorname{Re} 2=200, \operatorname{Rew}=100, \mathrm{H}=8 \mathrm{w}, \mathrm{r}=4 \mathrm{w})$.

The size of the cylinder and distance between the opposite jets were expected to be influential on the convective heat transfer performance. The flow pattern variations for different sizes $(\mathrm{H}=8 \mathrm{w})$ and different jet spacing $(\mathrm{r}=4 \mathrm{w})$ are shown in Figure 6a-f and Figure $6 \mathrm{~g}-1$. For larger cylinder sizes, the distance between the inlet port and impinging surface was reduced; and the vortex size near the inlet regions was affected when rotational surface effects were considered. However, the effects on the flow patterns variations became significant at the largest cylinder size. The distance effects between the opposite jets on the flow patterns are shown in Figure 6 without rotations (g-i) and with rotational surface effects $(j-1)$. At the highest distance, the recirculation regions near the inlet extended toward the cylinder while vortex size was increased. When rotations were considered, small vortices near the hot cylinder surface were established, while the impinging effects became weaker. For the flow dynamics and heat transfer, the size of the cylinder became influential when rotational surface effects were considered. The increment in the average $\mathrm{Nu}$ was $23.5 \%$ when varying the size from $\mathrm{r}=2 \mathrm{w}$ to $\mathrm{r}=6 \mathrm{w}$ at the highest rotational speed, and this value was only $1.5 \%$ without rotational effects (Figure $7 \mathrm{a}$ ). The trends in the average $\mathrm{Nu}$ while varying the opposite jet distances were different up to $\mathrm{H}=14 \mathrm{w}$, whether the rotations were active or not. As the rotations were present, the average $\mathrm{Nu}$ rose up to $\mathrm{H}=14 \mathrm{w}$ and then decreased from $\mathrm{H}=14 \mathrm{w}$ to $\mathrm{H}=16 \mathrm{w}$ (Figure $7 \mathrm{~b}$ ). This is attributed to the weakening of the impinging jet effects at the highest distance where flow field at the inlet zones was directed away from the hot surface of the cylinder. The optimum value of the distance between the jets was attained at $\mathrm{H}=14 \mathrm{w}$, where the average $\mathrm{Nu}$ value achieved its highest value for the case with a rotating cylinder-the highest cylinder. In this case, the increment in the average $\mathrm{Nu}$ was obtained as $54.5 \%$ when jet spacing at the smallest value was compared. There was a $30 \%$ reduction in the average $\mathrm{Nu}$ when cases at $\mathrm{H}=6 \mathrm{w}$ and $\mathrm{H}=14 \mathrm{w}$ were compared in the absence of rotational surface effects. 


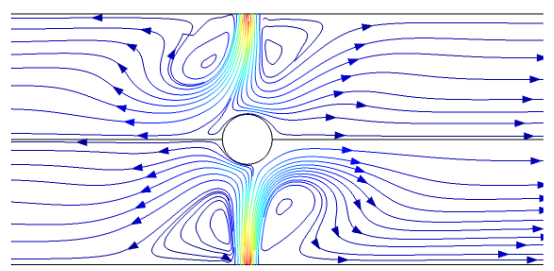

(a) r $=2 \mathrm{w}, \operatorname{Rew}=0$

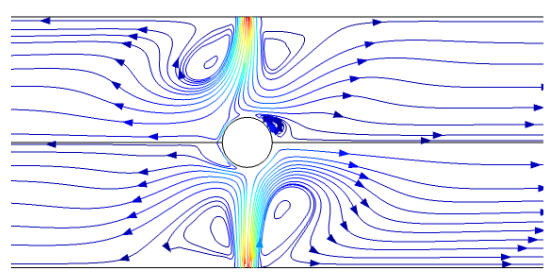

(d) r $=2 \mathrm{w}$, Rew $=800$

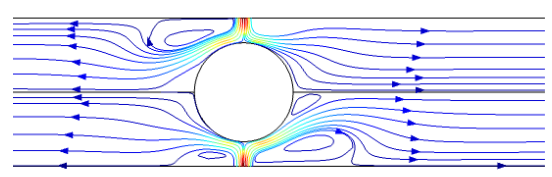

(g) $\mathrm{H}=6 \mathrm{w}, \mathrm{Rew}=0$

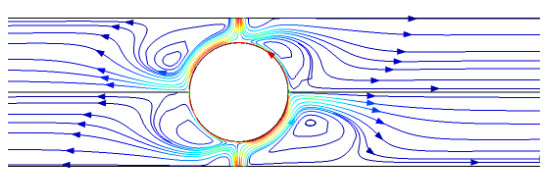

(j) $\mathrm{H}=6 \mathrm{w}$, Rew $=800$

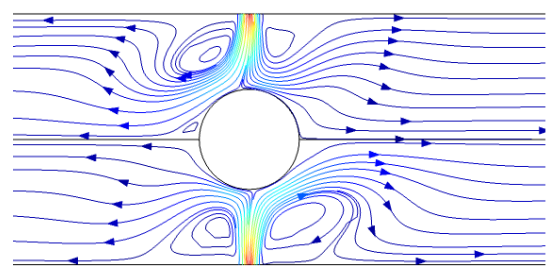

(b) $\mathrm{r}=4 \mathrm{w}$, Rew $=0$

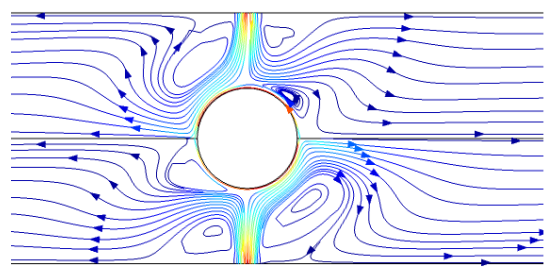

(e) $r=4 \mathrm{w}$, Rew $=800$

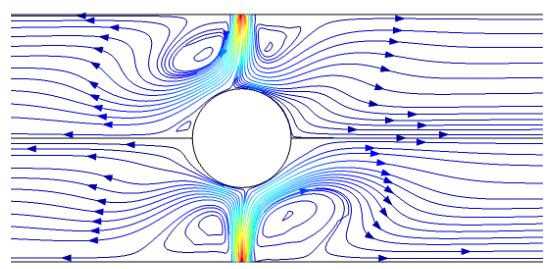

(h) $\mathrm{H}=10 \mathrm{w}$, Rew $=0$

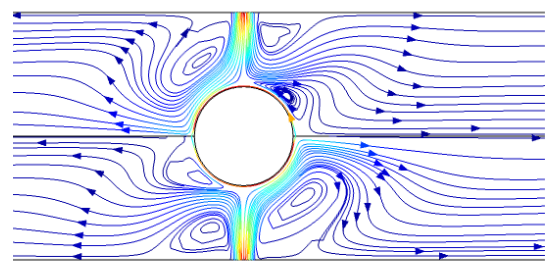

(k) $\mathrm{H}=10 \mathrm{w}$, Rew $=800$

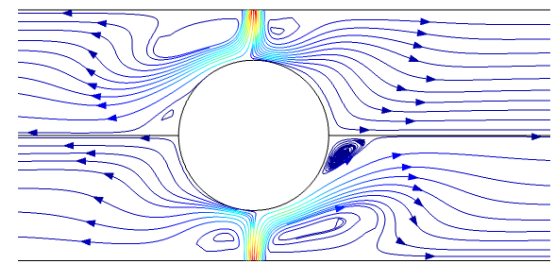

(c) $\mathrm{r}=6 \mathrm{w}$, Rew $=0$

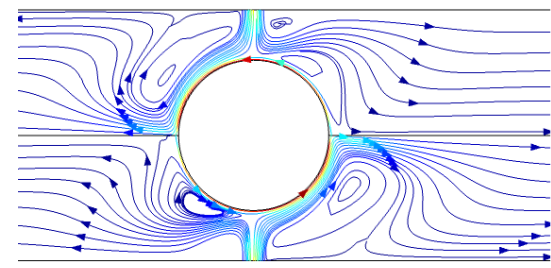

(f) $\mathrm{r}=6 \mathrm{w}$, Rew $=800$

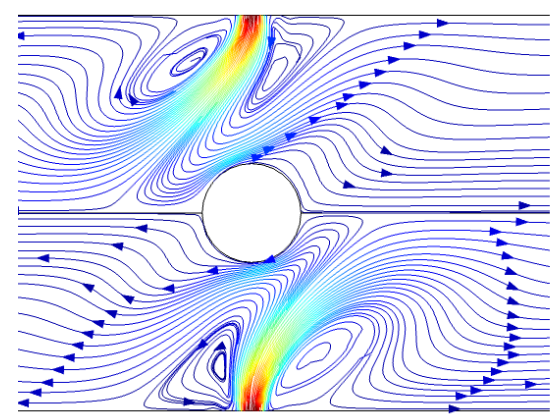

(i) $\mathrm{H}=16 \mathrm{w}, \operatorname{Rew}=0$

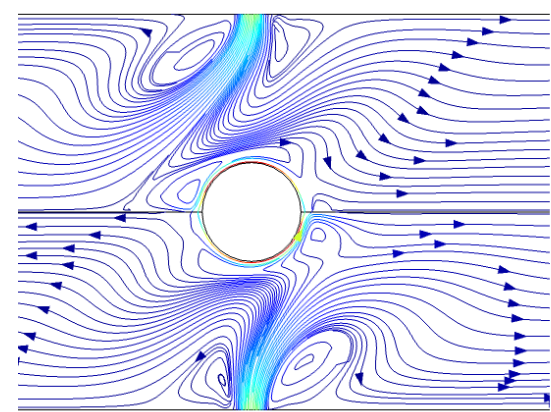

(1) $\mathrm{H}=16 \mathrm{w}$, Rew $=800$

Figure 6. Effects of the hot cylinder size on the streamline distributions for the cases without (a-c) and with (d-f) rotational surface $(\operatorname{Re} 1=\operatorname{Re} 2=300, \mathrm{Ha} 1=10, \mathrm{Ha} 2=7.5, \mathrm{H}=8 \mathrm{w})$; impacts of distance from the jets to interface boundary on the streamline variations in the absence $(\mathbf{g}-\mathbf{i})$ and presence $(\mathbf{j}-\mathbf{l})$ of rotations $(\operatorname{Re} 1=\operatorname{Re} 2=300, \mathrm{Ha} 1=10, \mathrm{Ha} 2=7.5, \mathrm{r}=4 \mathrm{w})$. 


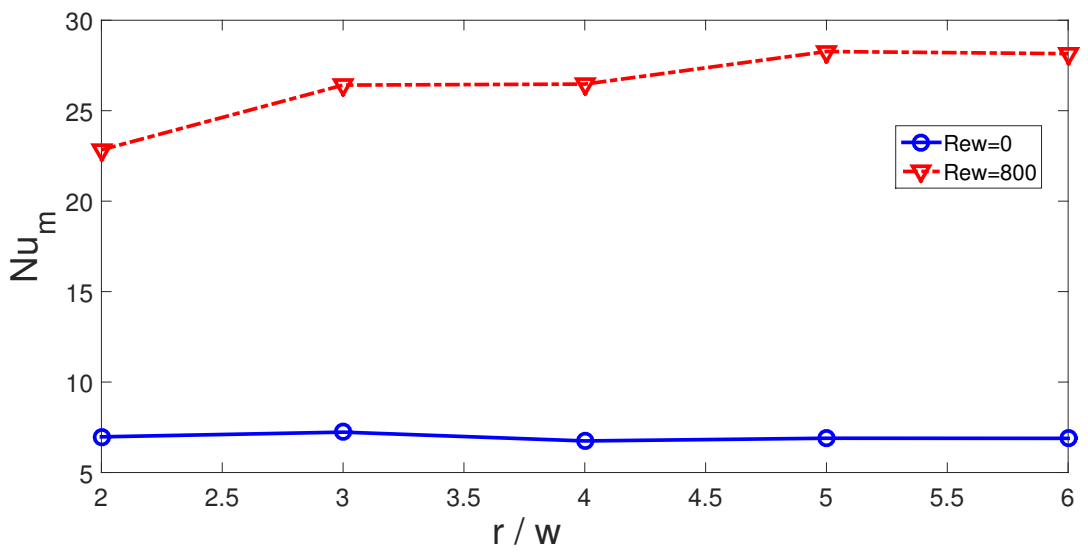

(a) $\mathrm{H}=8 \mathrm{w}$

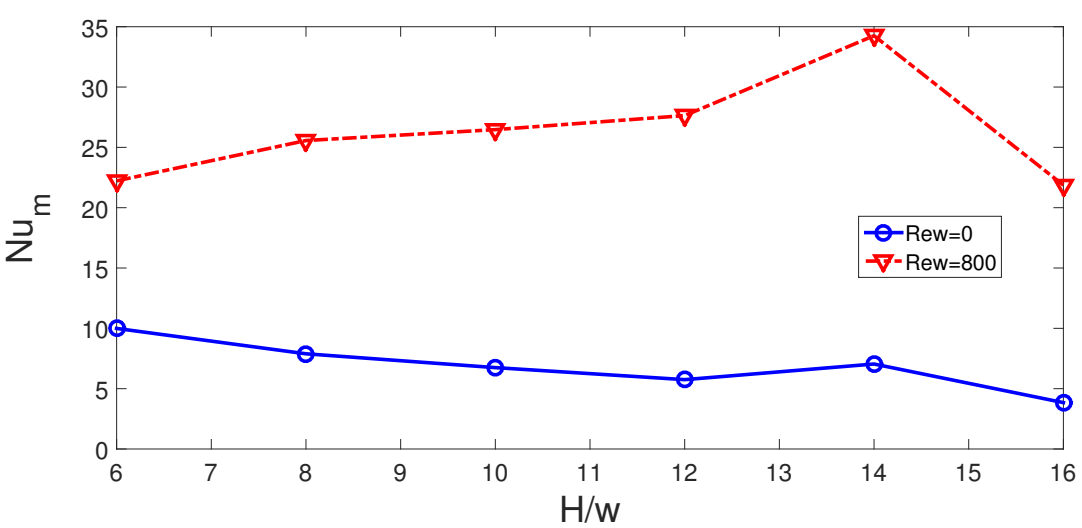

(b) $\mathrm{r}=4 \mathrm{w}$

Figure 7. Average $\mathrm{Nu}$ variations with changes in size of the cylinder (a) and distance from the jets to interface boundary $(\mathbf{b})(\operatorname{Re} 1=\operatorname{Re} 2=300, \mathrm{Ha} 1=10, \mathrm{Ha} 2=7.5)$.

\subsection{Modal Approach for Analyzing the Heat Transfer Dynamics}

The cooling performance was represented with average $\mathrm{Nu}$ from the hot rotating cylinder. Local values of $\mathrm{Nu}$ along the circumferential of the cylinder were collected, and modal analysis was performed. The proper orthogonal decomposition (POD) technique was used. The method was used for flow control, identification of flow dynamics, model order reduction and the parametric estimation of various thermo-fluid system performance factors [66-69]. The dataset for the local $\mathrm{Nu}$ along the R-C was collected for different values of Re, Rew and Ha. They are stated in terms of modal representation with POD modes multiplied by coefficients as:

$$
\mathrm{Nu}=\bar{N} u+\sum_{k=1}^{N} c_{k}(\operatorname{Re}, \operatorname{Rew}, \mathrm{Ha}) \Psi(x, y),
$$

where $N$ is the number of modes and $\Psi$ denotes the POD mode. Here, $c_{k}$ denotes the modal coefficient. The modes were obtained after solving the following integral eigenvalue problem:

$$
\int_{V}\left\langle K^{\prime}(\mathbf{x}) \otimes \mathbf{K}^{\prime}\left(\mathbf{x}^{\prime}\right)\right\rangle \Psi\left(\mathbf{x}^{\prime}\right) \mathbf{d}^{\prime}=\Lambda \Psi(\mathbf{x}),
$$

where the first term of the integral is the cross-correlation tensor, and $\Lambda$ denotes the eigenvalues. Singular value decomposition may also be used to get the modes. The largest energy content was captured with the first mode, and it is distributed in a hierarchical manner. Mode coefficients can be obtained after the projection of the dataset onto modes due to the orthogonality features of the modes. The number of spatial points in the dataset 
is 1032. Parametric variations of $\mathrm{Nu}$ with different $\mathrm{Re}$ (eight values), Rew (eight values) and Ha (eight values) were considered. The number of snapshots was $8 \times 8 \times 8=512$. The cumulative contribution (CC) of the modes was considered to determine the number of modes retained in the modal representation. For one, three and ten modes, the CC values were $0.681,0.860$ and 0.974 , respectively. In the present work, a twenty mode approximation was considered where the CC value was 0.995 . The modal coefficients are dependent upon the Re, Rew and Ha. The variations of several mode coefficients with varying Rew and Ha are presented in Figure 8a,b. The modal coefficients are sensitive to the variations in Rew and Ha. The reconstruction of the average $\mathrm{Nu}$ which denotes the cooling performance was achieved by superposing all of the modal coefficients multiplied by the corresponding modes. The modes were functions of spatial coordinates which were obtained with SVD. For any parameter of interest within the interval of Re, Rew and $\mathrm{Ha}$, interpolation among the modal coefficients could be utilized to determine the cooling performance at the specified parameter. Polynomials, splines and neural network-based approximations for the modal coefficients can be considered. Variations in the average $\mathrm{Nu}$ from the R-C with different numbers of modes are presented in Figure $8 \mathrm{c}-\mathrm{e}$. Table 2 presents the comparison results for the average $\mathrm{Nu}$ variations with different parametric combinations of ( $\mathrm{Re}, \mathrm{Ha}$, Rew) considering different numbers of modes. A 20-mode approximation of the $\mathrm{Nu}$ gave satisfactory results and captured the variations in $\mathrm{Re}$, Rew and $\mathrm{Ha}$ as compared to CFD.

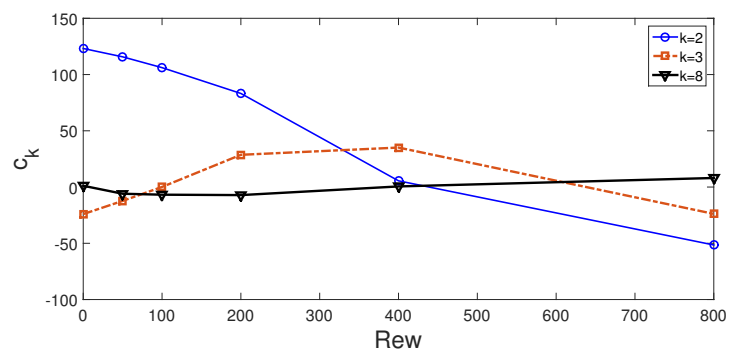

(a)

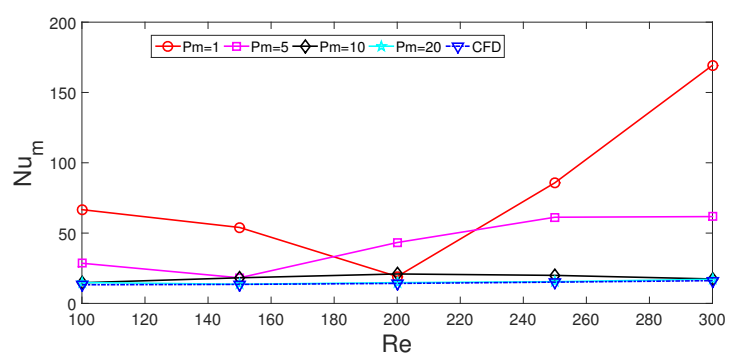

(c) Rew $=400, \mathrm{Ha} 1=10, \mathrm{Ha} 2=7.5$

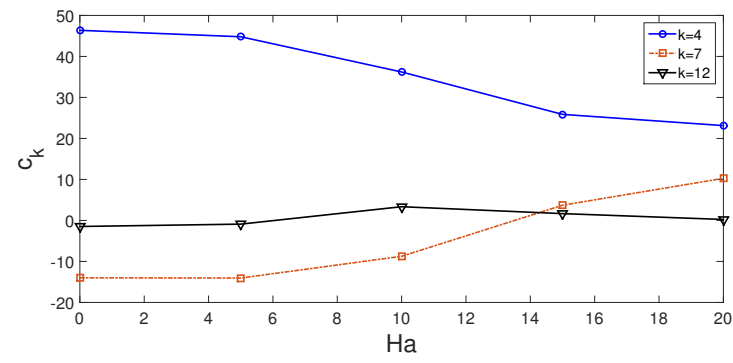

(b)

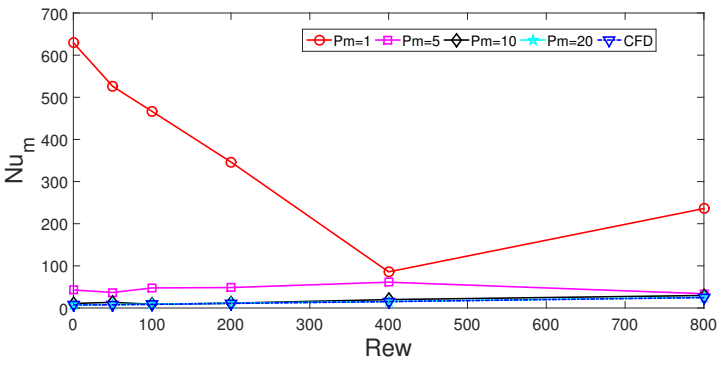

(d) $\mathrm{Re}=250, \mathrm{Ha} 1=10, \mathrm{Ha} 2=7.5$

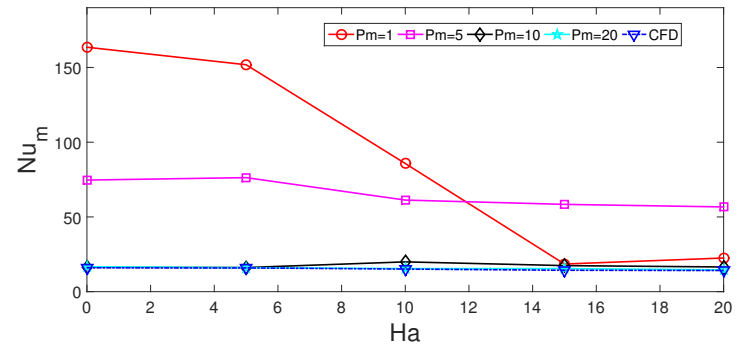

(e) $\operatorname{Re}=250$, Rew $=400, \mathrm{Ha} 2=7.5$

Figure 8. Modal coefficients' variations with changes in Rew (a), Ha (b) and approximation of average Nu from the hot cylinder with different numbers of modes and variations with respect to changes in $\operatorname{Re}(\mathbf{c}), \operatorname{Rew}(\mathbf{d})$ and Ha (e). 
Table 2. Comparisons of modal approximations of average $\mathrm{Nu}$ from the hot rotating cylinder with varying Re, Ha and Rew considering different numbers of modes.

\begin{tabular}{|c|c|c|c|c|c|c|c|}
\hline $\operatorname{Re}$ & Ha & Rew & $\mathrm{Nm}$ (CFD) & $\mathrm{Nm}(\mathrm{Pm}=20)$ & $\mathrm{Nm}(\mathrm{Pm}=10)$ & $\mathrm{Nm}(\mathrm{Pm}=5)$ & $\operatorname{Nm}(\operatorname{Pm}=1)$ \\
\hline 100.0000 & 0 & 0 & 6.2497 & 6.4462 & 9.5632 & 57.3214 & 545.8495 \\
\hline 100.0000 & 0 & 50.0000 & 6.8237 & 7.1213 & 11.9184 & 17.3907 & 462.4441 \\
\hline 100.0000 & 0 & 400.0000 & 14.6884 & 14.9741 & 18.6315 & 28.1527 & 80.9423 \\
\hline 100.0000 & 0 & 800.0000 & 24.5434 & 25.5128 & 31.3278 & 79.0200 & 200.1170 \\
\hline 100.0000 & 10.0000 & 0 & 5.6470 & 5.9361 & 7.1699 & 49.7720 & 493.4111 \\
\hline 100.0000 & 10.0000 & 100.0000 & 6.8706 & 6.9632 & 10.2770 & 7.4057 & 308.0403 \\
\hline 100.0000 & 10.0000 & 200.0000 & 8.8338 & 8.8570 & 8.9427 & 44.0794 & 179.6151 \\
\hline 100.0000 & 10.0000 & 800.0000 & 23.9908 & 24.1325 & 29.1065 & 83.9645 & 259.1009 \\
\hline 100.0000 & 20.0000 & 0 & 5.4673 & 5.5938 & 5.9929 & 54.9489 & 477.0083 \\
\hline 100.0000 & 20.0000 & 50.0000 & 6.0726 & 6.2576 & 7.0391 & 12.4069 & 391.0110 \\
\hline 100.0000 & 20.0000 & 100.0000 & 6.8875 & 6.9375 & 8.2319 & 15.3442 & 308.9107 \\
\hline 100.0000 & 20.0000 & 200.0000 & 8.7475 & 8.8960 & 8.7819 & 49.1804 & 167.7980 \\
\hline 100.0000 & 20.0000 & 400.0000 & 12.6457 & 12.9282 & 17.9019 & 22.0853 & 122.6875 \\
\hline 100.0000 & 20.0000 & 800.0000 & 21.6047 & 21.9554 & 32.6789 & 65.2207 & 469.4697 \\
\hline 200.0000 & 0 & 0 & 7.8387 & 7.9967 & 10.6971 & 74.6170 & 687.7526 \\
\hline 200.0000 & 0 & 50.0000 & 8.2268 & 8.4720 & 11.9520 & 9.6814 & 591.5352 \\
\hline 200.0000 & 0 & 100.0000 & 9.1310 & 9.2616 & 12.1394 & 29.0391 & 511.3187 \\
\hline 200.0000 & 0 & 200.0000 & 11.0642 & 11.3022 & 11.2247 & 30.8318 & 359.0287 \\
\hline 200.0000 & 0 & 800.0000 & 26.6669 & 26.6894 & 30.3759 & 30.5815 & 46.3589 \\
\hline 200.0000 & 10.0000 & 0 & 6.5669 & 6.8824 & 9.7931 & 44.4367 & 576.1642 \\
\hline 200.0000 & 10.0000 & 200.0000 & 10.0864 & 10.2961 & 10.6333 & 29.5709 & 272.8990 \\
\hline 200.0000 & 10.0000 & 400.0000 & 14.2078 & 14.3630 & 20.9316 & 43.2918 & 19.1135 \\
\hline 200.0000 & 10.0000 & 800.0000 & 24.1272 & 24.3464 & 30.2456 & 50.9392 & 265.3572 \\
\hline 200.0000 & 20.0000 & 0 & 6.2107 & 6.4886 & 7.4037 & 51.6364 & 544.8552 \\
\hline 200.0000 & 20.0000 & 50.0000 & 6.7583 & 6.9124 & 6.8784 & 7.2988 & 453.0497 \\
\hline 200.0000 & 20.0000 & 100.0000 & 7.6583 & 7.7101 & 8.7380 & 18.4243 & 374.5025 \\
\hline 200.0000 & 20.0000 & 800.0000 & 22.6811 & 22.2298 & 28.6700 & 32.9669 & 409.4980 \\
\hline 300.0000 & 0 & 0 & 9.7896 & 9.8251 & 15.7833 & 81.4567 & 862.7452 \\
\hline 300.0000 & 0 & 50.0000 & 9.9599 & 10.072 & 15.3358 & 18.1471 & 755.0554 \\
\hline 300.0000 & 0 & 100.0000 & 10.8957 & 11.1617 & 14.1908 & 51.4394 & 675.1634 \\
\hline 300.0000 & 0 & 200.0000 & 13.0772 & 13.2291 & 18.3195 & 83.1912 & 545.4293 \\
\hline 300.0000 & 0 & 400.0000 & 17.2439 & 17.5309 & 18.8414 & 71.4711 & 263.1526 \\
\hline 300.0000 & 0 & 800.0000 & 26.8919 & 27.1330 & 27.4019 & 66.5719 & 50.5082 \\
\hline 300.0000 & 10.0000 & 0 & 7.8904 & 7.9299 & 11.7347 & 38.9112 & 694.0833 \\
\hline 300.0000 & 10.0000 & 50.0000 & 8.1642 & 8.26032 & 16.6721 & 48.1251 & 584.9435 \\
\hline 300.0000 & 10.0000 & 100.0000 & 9.2769 & 9.43595 & 10.6890 & 61.3910 & 526.4681 \\
\hline 300.0000 & 10.0000 & 200.0000 & 11.7848 & 11.9949 & 14.8063 & 77.0788 & 427.1771 \\
\hline 300.0000 & 10.0000 & 400.0000 & 16.1658 & 16.1997 & 17.3894 & 61.7393 & 169.3253 \\
\hline 300.0000 & 10.0000 & 800.0000 & 25.5614 & 25.8692 & 29.0225 & 73.8450 & 180.4926 \\
\hline 300.0000 & 20.0000 & 0 & 6.9272 & 6.9962 & 8.6297 & 44.9572 & 609.7692 \\
\hline 300.0000 & 20.0000 & 50.0000 & 7.4184 & 7.5229 & 7.8931 & 20.1793 & 514.5291 \\
\hline 300.0000 & 20.0000 & 100.0000 & 8.3501 & 8.4897 & 8.8413 & 37.1866 & 438.6225 \\
\hline 300.0000 & 20.0000 & 200.0000 & 10.5743 & 10.8618 & 13.3447 & 46.6147 & 313.8373 \\
\hline 300.0000 & 20.0000 & 400.0000 & 14.8214 & 14.98553 & 16.2357 & 66.1440 & 57.5720 \\
\hline 300.0000 & 20.0000 & 800.0000 & 24.1676 & 24.3551 & 30.1478 & 81.6907 & 308.1989 \\
\hline
\end{tabular}

\section{Conclusions}

In the current study, convective HT performance for impinging jets onto a rotating hot circular cylinder was numerically assessed under multiple MaF effects. Binary nanoparticles were used in the HT fluid, and different strengths of MaF were considered in the opposing jet domains. The following conclusions were drawn from the numerical simulation results:

- The coupled interactions between the rotating hot body, forced flow of hybrid nanofluid and multiple magnetic field effects determine the flow recirculations with the systems and heat transfer enhancement amounts. 
- When the rotational surface effects are dominant, the impacts of Re on the average $\mathrm{Nu}$ increase become weak as compared to motionless cylinder case. When the lowest and highest Re cases were compared, a 5\% rise of average $\mathrm{Nu}$ was seen at Rew $=800$, and it was $48.5 \%$ at Rew $=0$.

- Impacts of rotation on the HT enhancement are significant when MaF effects are present in the system. The average $\mathrm{Nu}$ rose by about $249 \%$ at $\mathrm{Ha} 1=0$, and it was only $175 \%$ at $\mathrm{Ha} 1=0$.

- When the configuration in the presence of MaF effects at the highest strength is compared with the case in the absence of MaF in both domains, a 54.5\% reduction in the average $\mathrm{Nu}$ was obtained.

- When cases with the smallest and highest cylinder sizes were compared at the highest rotational speeds, the increment in the average $\mathrm{Nu}$ was observed as $23.5 \%$.

- $\quad$ The optimum value of distance between the opposing jets was obtained at $\mathrm{H}=14 \mathrm{w}$ for the maximum $\mathrm{HT}$, where a $54.5 \%$ rise in the average $\mathrm{Nu}$ was attained as compared to the case at the smallest spacing.

- A modal analysis of the local Nu was proposed with 20-modes, with varying Re, Rew and Ha parameters.

The present work may be extended to include unsteady flow effects, different thermal boundary conditions, multiple rotating cylinder configurations, non-uniform magnetic field effects and different nanoparticle types. A multi-domain POD approach may also be utilized where different numbers of modes for the lower and upper domains may be considered. Efficient interpolation methods may also be used among the modal coefficients which are dependent upon the parameters to predict the cooling performance of the system. These will increase the applicability of the present configuration to diverse energy system technologies.

Author Contributions: Conceptualization, F.S.; methodology, F.S., L.K. and B.A.; software, F.S.; validation, L.K.; formal analysis, F.S., F.A. and L.K.; investigation, F.S., L.K. and B.A.; writing-original draft preparation, F.S.; writing-review and editing, F.S., B.A., L.K., W.A. and L.B.S.; visualization, F.S. and L.K.; supervision, F.S., B.A., L.K., W.A. and L.B.S. All authors have read and agreed to the published version of the manuscript.

Funding: This research has been funded by Scientific Research Deanship at University of Ha'il Saudi Arabia through project number RG-21 057.

Institutional Review Board Statement: Not applicable.

Informed Consent Statement: Not applicable.

Conflicts of Interest: The authors declare no conflict of interest.

$\begin{array}{ll}\text { Abbreviations } & \\ B & \text { magnetic field strength } \\ C C & \text { cumulative contribution } \\ c_{k} & \text { mode coefficient } \\ D_{h} & \text { hydraulic diameter } \\ h & \text { local heat transfer coefficient } \\ H & \text { distance between the jet and interface } \\ \mathrm{Ha} & \text { Hartmann number } \\ k & \text { thermal conductivity } \\ L & \text { plate length } \\ n & \text { surface normal } \\ \mathrm{Nu} & \text { Nusselt number } \\ p & \text { pressure }\end{array}$




\begin{tabular}{|c|c|}
\hline Pm & mode number \\
\hline $\operatorname{Pr}$ & Prandtl number \\
\hline Rew & rotational Reynolds number \\
\hline $\operatorname{Re}$ & Reynolds number \\
\hline$r$ & cylinder radius \\
\hline$T$ & temperature \\
\hline$u, v$ & $x-y$ velocity components \\
\hline$W$ & weight function \\
\hline$x, y$ & Cartesian coordinates \\
\hline$x_{c}, y_{c}$ & cylinder center \\
\hline Greek Characters & \\
\hline$\alpha$ & thermal diffusivity \\
\hline$\phi$ & solid volume fraction \\
\hline$v$ & kinematic viscosity \\
\hline$\theta$ & non-dimensional temperature \\
\hline$\rho$ & density of the fluid \\
\hline$\gamma$ & inclination angle \\
\hline \multicolumn{2}{|l|}{ Subscripts } \\
\hline$c$ & cold \\
\hline$h$ & hot \\
\hline$m$ & average \\
\hline$n f$ & nanofluid \\
\hline$p$ & solid particle \\
\hline
\end{tabular}

\section{References}

1. Garimella, S.V. Heat transfer and flow fields in confined jet impingement. Annu. Rev. Heat Transf. 2000, 11, 413-494. [CrossRef]

2. Jambunathan, K.; Lai, E.; Moss, M.; Button, B. A review of heat transfer data for single circular jet impingement. Int. J. Heat Fluid Flow 1992, 13, 106-115. [CrossRef]

3. Sarkar, A.; Nitin, N.; Karwe, M.; Singh, R.P. Fluid flow and heat transfer in air jet impingement in food processing. J. Food Sci. 2004, 69, CRH113-CRH122. [CrossRef]

4. Nadda, R.; Kumar, A.; Maithani, R. Efficiency improvement of solar photovoltaic/solar air collectors by using impingement jets: A review. Renew. Sustain. Energy Rev. 2018, 93, 331-353. [CrossRef]

5. Sajid, M.U.; Ali, H.M. Recent advances in application of nanofluids in heat transfer devices: A critical review. Renew. Sustain. Energy Rev. 2019, 103, 556-592. [CrossRef]

6. Pordanjani, A.H.; Aghakhani, S.; Afrand, M.; Mahmoudi, B.; Mahian, O.; Wongwises, S. An updated review on application of nanofluids in heat exchangers for saving energy. Energy Convers. Manag. 2019, 198, 111886. [CrossRef]

7. Khanafer, K.; Vafai, K. A review on the applications of nanofluids in solar energy field. Renew. Energy 2018, 123, 398-406. [CrossRef]

8. Aly, A.M.; Mohamed, E.M.; Alsedais, N. The magnetic field on a nanofluid flow within a finned cavity containing solid particles. Case Stud. Therm. Eng. 2021, 25, 100945. [CrossRef]

9. Kakaç, S.; Pramuanjaroenkij, A. Single-phase and two-phase treatments of convective heat transfer enhancement with nanofluidsA state-of-the-art review. Int. J. Therm. Sci. 2016, 100, 75-97. [CrossRef]

10. Ahmed, F. Experimental investigation of $\mathrm{Al}_{2} \mathrm{O}_{3}$-water nanofluid as a secondary fluid in a refrigeration system. Case Stud. Therm. Eng. 2021, 101024. [CrossRef]

11. Kareem, Z.S.; Balla, H.H.; AbdulWahid, A.F. Heat transfer enhancement in single circular impingement jet by CuO-water nanofluid. Case Stud. Therm. Eng. 2019, 15, 100508. [CrossRef]

12. Manca, O.; Mesolella, P.; Nardini, S.; Ricci, D. Numerical study of a confined slot impinging jet with nanofluids. Nanoscale Res. Lett. 2011, 6, 1-16. [CrossRef]

13. Barewar, S.D.; Tawri, S.; Chougule, S.S. Heat transfer characteristics of free nanofluid impinging jet on flat surface with different jet to plate distance: An experimental investigation. Chem. Eng. Process.-Process. Intensif. 2019, 136, 1-10. [CrossRef]

14. Lamraoui, H.; Mansouri, K.; Saci, R. Numerical investigation on fluid dynamic and thermal behavior of a non-Newtonian $\mathrm{Al}_{2} \mathrm{O}_{3}$-water nanofluid flow in a confined impinging slot jet. J. Non-Newton. Fluid Mech. 2019, 265, 11-27. [CrossRef]

15. Balla, H.H.; Hashem, A.L.; Kareem, Z.S.; Abdulwahid, A.F. Heat transfer potentials of ZnO/water nanofluid in free impingement jet. Case Stud. Therm. Eng. 2021, 27, 101143. [CrossRef]

16. Mohammadpour, J.; Lee, A. Investigation of nanoparticle effects on jet impingement heat transfer: A review. J. Mol. Liq. 2020, 316, 113819. [CrossRef]

17. Teamah, M.A.; Dawood, M.M.K.; Shehata, A. Numerical and experimental investigation of flow structure and behavior of nanofluids flow impingement on horizontal flat plate. Exp. Therm. Fluid Sci. 2016, 74, 235-246. [CrossRef] 
18. Naphon, P.; Wiriyasart, S. Pulsating flow and magnetic field effects on the convective heat transfer of $\mathrm{TiO}_{2}$-water nanofluids in helically corrugated tube. Int. J. Heat Mass Transf. 2018, 125, 1054-1060. [CrossRef]

19. Buonomo, B.; Manca, O.; Bondareva, N.S.; Sheremet, M.A. Thermal and fluid dynamic behaviors of confined slot jets impinging on an isothermal moving surface with nanofluids. Energies 2019, 12, 2074. [CrossRef]

20. Selimefendigil, F.; Öztop, H.F. Numerical study and identification of cooling of heated blocks in pulsating channel flow with a rotating cylinder. Int. J. Therm. Sci. 2014, 79, 132-145. [CrossRef]

21. Akdag, U.; Akcay, S.; Demiral, D. Heat transfer enhancement with laminar pulsating nanofluid flow in a wavy channel. Int. Commun. Heat Mass Transf. 2014, 59, 17-23. [CrossRef]

22. Mitra, S.; Saha, S.K.; Chakraborty, S.; Das, S. Study on boiling heat transfer of water-TiO 2 and water-MWCNT nanofluids based laminar jet impingement on heated steel surface. Appl. Therm. Eng. 2012, 37, 353-359. [CrossRef]

23. Liu, Z.H.; Qiu, Y.H. Boiling heat transfer characteristics of nanofluids jet impingement on a plate surface. Heat Mass Transf. 2007, 43, 699-706. [CrossRef]

24. Li, P.; Guo, D.; Liu, R. Mechanism analysis of heat transfer and flow structure of periodic pulsating nanofluids slot-jet impingement with different waveforms. Appl. Therm. Eng. 2019, 152, 937-945. [CrossRef]

25. Mahdavi, M.; Sharifpur, M.; Meyer, J.P. Fluid flow and heat transfer analysis of nanofluid jet cooling on a hot surface with various roughness. Int. Commun. Heat Mass Transf. 2020, 118, 104842. [CrossRef]

26. Singh, T.P.; Kumar, A.; Satapathy, A.K. Role of a Sinusoidal Wavy Surface in Enhancement of Heat Transfer Using Turbulent Dual Jet. J. Heat Transf. 2021, 143, 032002. [CrossRef]

27. Selimefendigil, F.; Öztop, H.F. Forced convection and thermal predictions of pulsating nanofluid flow over a backward facing step with a corrugated bottom wall. Int. J. Heat Mass Transf. 2017, 110, 231-247. [CrossRef]

28. Roslan, R.; Saleh, H.; Hashim, I. Effect of rotating cylinder on heat transfer in a square enclosure filled with nanofluids. Int. J. Heat Mass Transf. 2012, 55, 7247-7256. [CrossRef]

29. Khanafer, K.; Aithal, S.M.; Vafai, K. Mixed convection heat transfer in a differentially heated cavity with two rotating cylinders. Int. J. Therm. Sci. 2019, 135, 117-132. [CrossRef]

30. Selimefendigil, F.; Oztop, H.F. Analysis and predictive modeling of nanofluid-jet impingement cooling of an isothermal surface under the influence of a rotating cylinder. Int. J. Heat Mass Transf. 2018, 121, 233-245.

31. Benim, A.C.; Ozkan, K.; Cagan, M.; Gunes, D. Computational investigation of turbulent jet impinging onto rotating disk. Int. J. Numer. Methods Heat Fluid Flow 2007, 17, 284-301. [CrossRef]

32. Jeng, T.M.; Tzeng, S.C.; Xu, R. Heat transfer characteristics of a rotating cylinder with a lateral air impinging jet. Int. J. Heat Mass Transf. 2014, 70, 235-249. [CrossRef]

33. Scheichl, B.; Kluwick, A. Laminar spread of a circular liquid jet impinging axially on a rotating disc. J. Fluid Mech. 2019, 864, 449-489. [CrossRef]

34. Chen, Y.M.; Wang, K.C. Experimental study on the forced convective flow in a channel with heated blocks in tandem. Exp. Therm. Fluid Sci. 1998, 16, 286-298. [CrossRef]

35. Kabeel, A.; El-Said, E.M.; Dafea, S. A review of magnetic field effects on flow and heat transfer in liquids: Present status and future potential for studies and applications. Renew. Sustain. Energy Rev. 2015, 45, 830-837. [CrossRef]

36. Sheikholeslami, M.; Rokni, H.B. Magnetohydrodynamic CuO-water nanofluid in a porous complex-shaped enclosure. J. Therm. Sci. Eng. Appl. 2017, 9, 041007. [CrossRef]

37. Nesliturk, A.I.; Tezer-Sezgin, M. The finite element method for MHD flow at high Hartmann numbers. Comput. Methods Appl. Mech. Eng. 2005, 194, 1201-1224. [CrossRef]

38. Nguyen, T.T.; Bouillault, F.; Daniel, L.; Mininger, X. Finite element modeling of magnetic field sensors based on nonlinear magnetoelectric effect. J. Appl. Phys. 2011, 109, 084904. [CrossRef]

39. Lee, S.H.; Kim, Y.S. Finite element analysis for cooling effect of magnetic fluid with alternating magnetic field. J. Appl. Phys. 2009, 105, 07B510. [CrossRef]

40. Selimefendigil, F.; Öztop, H.F. Corrugated conductive partition effects on MHD free convection of CNT-water nanofluid in a cavity. Int. J. Heat Mass Transf. 2019, 129, 265-277. [CrossRef]

41. Ansari, S.; Farquharson, C.G. 3D finite-element forward modeling of electromagnetic data using vector and scalar potentials and unstructured grids. Geophysics 2014, 79, E149-E165. [CrossRef]

42. Yin, W.; Lu, M.; Yin, L.; Zhao, Q.; Meng, X.; Zhang, Z.; Peyton, A. Acceleration of eddy current computation for scanning probes. Insight-Non-Destr. Test. Cond. Monit. 2018, 60, 547-555. [CrossRef]

43. Huang, R.; Lu, M.; Peyton, A.; Yin, W. A novel perturbed matrix inversion based method for the acceleration of finite element analysis in crack-scanning eddy current NDT. IEEE Access 2020, 8, 12438-12444. [CrossRef]

44. Kumar, M.A.; Reddy, Y.D.; Rao, V.S.; Goud, B.S. Thermal radiation impact on MHD heat transfer natural convective nano fluid flow over an impulsively started vertical plate. Case Stud. Therm. Eng. 2021, 24, 100826. [CrossRef]

45. Ghasemi, B.; Aminossadati, S.; Raisi, A. Magnetic field effect on natural convection in a nanofluid-filled square enclosure. Int. J. Therm. Sci. 2011, 50, 1748-1756. [CrossRef]

46. Waqas, H.; Farooq, U.; Naseem, R.; Hussain, S.; Alghamdi, M. Impact of MHD radiative flow of hybrid nanofluid over a rotating disk. Case Stud. Therm. Eng. 2021, 26, 101015. [CrossRef] 
47. Sheremet, M.A.; Oztop, H.; Pop, I.; Al-Salem, K. MHD free convection in a wavy open porous tall cavity filled with nanofluids under an effect of corner heater. Int. J. Heat Mass Transf. 2016, 103, 955-964. [CrossRef]

48. Ma, Y.; Mohebbi, R.; Rashidi, M.M.; Yang, Z. MHD convective heat transfer of Ag-MgO/water hybrid nanofluid in a channel with active heaters and coolers. Int. J. Heat Mass Transf. 2019, 137, 714-726. [CrossRef]

49. Khalid, A.; Khan, I.; Khan, A.; Shafie, S.; Tlili, I. Case study of MHD blood flow in a porous medium with CNTS and thermal analysis. Case Stud. Therm. Eng. 2018, 12, 374-380. [CrossRef]

50. Kolsi, L.; Alrashed, A.A.A.A.; Al-Salem, K.; Oztop, H.F.; Borjini, M.N. Control of natural convection via inclined plate of CNT-water nanofluid in an open sided cubical enclosure under magnetic field. Int. J. Heat Mass Transf. 2017, 111, 1007-1018. [CrossRef]

51. Naphon, P.; Wiriyasart, S. Pulsating $\mathrm{TiO}_{2}$ / water nanofluids flow and heat transfer in the spirally coiled tubes with different magnetic field directions. Int. J. Heat Mass Transf. 2017, 115, 537-543. [CrossRef]

52. Sheikholeslami, M.; Mahian, O. Enhancement of PCM solidification using inorganic nanoparticles and an external magnetic field with application in energy storage systems. J. Clean. Prod. 2019, 215, 963-977. [CrossRef]

53. Aidaoui, L.; Lasbet, Y.; Selimefendigil, F. Improvement of transfer phenomena rates in open chaotic flow of nanofluid under the effect of magnetic field: Application of a combined method. Int. J. Mech. Sci. 2020, 179, 105649. [CrossRef]

54. Lee, H.; Ha, M.; Yoon, H. A numerical study on the fluid flow and heat transfer in the confined jet flow in the presence of magnetic field. Int. J. Heat Mass Transf. 2005, 48, 5297-5309. [CrossRef]

55. Nishiyama, H.; Kuzuhara, M.; Solonenko, O.; Kamiyama, S. Numerical modeling of an impinging and compressible dusted plasma jet controlled by a magnetic field. Plasma Chem. Plasma Process. 1999, 19, 363-381. [CrossRef]

56. Selimefendigil, F.; Öztop, H.F. $\mathrm{Al}_{2} \mathrm{O}_{3}$-water nanofluid jet impingement cooling with magnetic field. Heat Transf. Eng. 2020, 41, 50-64. [CrossRef]

57. Nimmagadda, R.; Haustein, H.D.; Asirvatham, L.G.; Wongwises, S. Effect of uniform/non-uniform magnetic field and jet impingement on the hydrodynamic and heat transfer performance of nanofluids. J. Magn. Magn. Mater. 2019, 479, $268-281$. [CrossRef]

58. Abbassi, H.; Nassrallah, S.B. MHD flow and heat transfer in a backward-facing step. Int. Commun. Heat Mass Transf. 2007, 34, 231-237. [CrossRef]

59. Hussain, S.; Ahmed, S.E. Unsteady MHD forced convection over a backward facing step including a rotating cylinder utilizing $\mathrm{Fe}_{3} \mathrm{O}_{4}$-water ferrofluid. J. Magn. Magn. Mater. 2019, 484, 356-366. [CrossRef]

60. Selimefendigil, F.; Öztop, H.F. Hydro-thermal performance of CNT nanofluid in double backward facing step with rotating tube bundle under magnetic field. Int. J. Mech. Sci. 2020, 185, 105876. [CrossRef]

61. Urmi, W.; Rahman, M.; Hamzah, W. An experimental investigation on the thermophysical properties of $40 \%$ ethylene glycol based $\mathrm{TiO}_{2}-\mathrm{Al}_{2} \mathrm{O}_{3}$ hybrid nanofluids. Int. Commun. Heat Mass Transf. 2020, 116, 104663. [CrossRef]

62. Sahoo, D.; Sharif, M. Numerical modeling of slot-jet impingement cooling of a constant heat flux surface confined by a parallel wall. Int. J. Therm. Sci. 2004, 43, 877-887. [CrossRef]

63. Chou, Y.; Hung, Y. Impingement cooling of an isothermally heated surface with a confined slot jet. ASME Trans. J. Heat Transf. 1994, 116, 479-482. [CrossRef]

64. Manca, O.; Ricci, D.; Nardini, S.; Di Lorenzo, G. Thermal and fluid dynamic behaviors of confined laminar impinging slot jets with nanofluids. Int. Commun. Heat Mass Transf. 2016, 70, 15-26. [CrossRef]

65. Zhang, T.; Che, D. Double MRT thermal lattice Boltzmann simulation for MHD natural convection of nanofluids in an inclined cavity with four square heat sources. Int. J. Heat Mass Transf. 2016, 94, 87-100. [CrossRef]

66. Berkooz, G.; Lumley, P.H.J.L. The proper orthogonal decomposition in the analysis of turbulent flows. Annu. Rev. Fluid Mech. 1993, 25, 539-575. [CrossRef]

67. Sirisup, S.; Karniadakis, G.E. Stability and accuracy of periodic flow solutions obtained by a POD-penalty method. J. Phys. D 2005, 202, 218-237. [CrossRef]

68. Hasan, N.; Sanghi, S. Proper orthogonal decomposition and low-dimensional modelling of thermally driven two-dimensional flow in a horizontal rotating flow. J. Fluid Mech. 2007, 573, 265-295. [CrossRef]

69. Selimefendigil, F.; Polifke, W. Nonlinear, proper-orthogonal-decomposition-based model of forced convection heat transfer in pulsating flow. AIAA J. 2014, 52, 131-145. [CrossRef] 